\title{
Noni - An Effective Solution for Denture Storage
}

\author{
Surabhi Duggal ${ }^{1}$, Karthikeyan Vaishnavi², D. Mohanalakshmi³ ${ }^{3}$ Megha Chopra ${ }^{4}$ \\ ${ }^{1,4}$ Department of Prosthodontics and Crown \& Bridge, School of Dental Sciences, Sharda \\ University, Greater Noida, Uttar Pradesh, India. 2,3 Department of Prosthodontics and Crown \& \\ Bridge, SRM Kattankulathur Dental College, SRM University, Chennai, Tamilnadu, India.
}

\section{ABSTRACT}

\section{BACKGROUND}

A plant extract of Morinda citrifolia has been known as an analgesic to treat and heal patients with various health problems ranging from body aches to microbial infections. Every component of this medicinal plant can be made use of to cure diabetes and many other systemic disorders. The role of Morinda citrifolia in dentistry is mostly limited to endodontics, whereas not much evidence is seen in the area of prosthetic dentistry. Hence, the present study has been conducted to study the effects of this magical plant extract on storage and disinfection of acrylic dentures.

\section{METHODS}

Samples of ten rectangular heat-cured polymethylmethacrylate resin moulds were fabricated by the traditional technique of denture processing. Five specimens were dipped in distilled water (Group 1) and the other five specimens were immersed in Morinda citrifolia (Group 2) for 20 days after which they were subjected to UTM testing to evaluate flexural strength. Results were analysed using Mann Whitney Utest $(\mathrm{P}<0.05)$.

\section{RESULTS}

Statistical analysis proves that polymethylmethacrylate slices immersed in the test group (Morinda citrifolia / group 2) showed superior thermal conductivity than the control group $(\mathrm{P}=0.028)$.

\section{CONCLUSIONS}

The flexural strength of Polymethylmethacrylate had increased after storing in Morinda citrifolia for twenty days when compared to storage in distilled water. Thus, Morinda citrifolia can be used as an effective storage medium without any changes in the flexural strength.

\section{KEY WORDS}

Plant Extract in Dentistry, Thermal Conductivity, Heat Cure Acrylic Resin, Geriatric Patients
Corresponding Author:

Dr. Surabhi Duggal,

Assistant Professor,

Department of Prosthodontics and Crown \& Bridge, School of Dental

Sciences, Sharda University,

Plot No. 32, 34, Knowledge Park III,

Greater Noida, U.P., India - 201310

E-mail: surabhiduggal92@gmail.com

DOI: $10.14260 / j e m d s / 2021 / 245$

How to Cite This Article:

Duggal S, Vaishnavi K, Mohanalakshmi D, et al. Noni - an effective solution for denture storage. J Evolution Med Dent Sci 2021;10(16):1150-1155, DOI: $10.14260 /$ jemds $/ 2021 / 245$

Submission 08-12-2020, Peer Review 19-02-2021, Acceptance 25-02-2021, Published 19-04-2021.

Copyright (C) 2021 Surabhi Duggal et al. This is an open access article distributed under Creative Commons Attribution License [Attribution 4.0 International (CC BY 4.0)] 


\section{BACKGROUND}

Polymethyl methyl acrylate (abbreviated as PMMA) has been utilised clinically for more than 70 years in dentistry as a dental material for the removable complete and partial prosthesis. They were first discovered by Dr. Walter Wright in the year 1937 after which acrylic resins have been successfully employed as denture bases, artificial teeth, repair of teeth and dentures as well as impression trays and even extensions of impression trays. ${ }^{1}$ Acrylic resins have widely contributed to the field of prosthetic dentistry as a denture base material. They possess ideal mechanical and physical properties apart from biocompatibility and aesthetics, adequate flexural strength, impact strength, and toughness. They are also low in cost and stable in the oral environment. A replacement of acrylic denture base resins has not yet been found. To date, they serve as the best material when concerned with geriatric dentistry. However, these acrylic resins have certain drawbacks. Their ability to absorb liquids and susceptibility to aggregate food debris draws the attention of the user as well as the dentist. This allows for easy and fast growth of microorganisms leading to the establishment and maturation of plaque.

An agglomeration of plaque is usually seen on the tissue surface of the maxillary and mandibular dentures in addition to the mandibular polished and shiny lingual borders. ${ }^{2}$ This increases the levels of Candida albicans causing a rise in the production of toxins, leading to inflammation. There is a meaningful correlation between awful oral hygiene, denture maintenance, and irritation, and redness of the tissues in the oral cavity. ${ }^{2}$ Complete denture treatment is considered successful only by the long-term maintenance of prosthesis by the patient. As most complete denture wearers are geriatric patients with systemic diseases, their compromised immunity can lead to accumulation and adhesion of bacteria and fungi on the denture surfaces. Elderly people most often store their dentures in water. To prevent the multiplication of micro pathogens such as Candida albicans aged edentulous individuals should make it a point to soak their dentures in a non-harmful disinfectant. Candida albicans have the potential to cause denture stomatitis so the habit of rinsing with a mild antiseptic mouthwash should be insisted on. ${ }^{2}$ Thus, to maintain denture hygiene various chemical disinfectants have been suggested.

A plant extract (Morinda citrifolia) has been found to have disinfectant properties and can be used for soaking heatactivated acrylic resins without adverse effects on its surface properties.

"Morinda citrifolia" known as 'Indian mulberry', 'beach mulberry' or as is commonly addressed to 'Noni' (Figure 1) is a medicinal plant having comprehensive curative reactions. ${ }^{3}$ All the parts of the plant including its roots, leaves, and fruits are being prescribed for numerous health issues. Its extract is a well-known therapeutic beverage employed to cure many diseases such as pain of the muscle and joints, heart diseases, GIT disturbances, and cancer. Apart from this, it is also a proven antiviral, antifungal, and an anti-parasitic agent ${ }^{3}$ that is specifically effective against Escherichia coli, Staphylococcus aureus, and Pseudomonas aeruginosa. Morinda citrifolia contains saponin, flavonoid, atsiri oil, and alkaloids that help fight against these microorganisms. It can also be employed as a swishing agent other than its use as a juice. As a mouthwash
Morinda citrifolia can be used twice or thrice a day. ${ }^{2}$ The literature describes the extensive use of Morinda citrifolia in the field of endodontics as an anti-cariogenic agent. Very few studies have been conducted to check the efficacy of Noni as a storage medium.

Thus, the present study was aimed at evaluating the flexural strength of polished heat-cured acrylic denture base resins after storage in distilled water and Morinda citrifolia (Noni).

The null hypothesis is that there is no difference between the flexural properties of specimens stored in distilled water and Noni.

\section{METHODS}

The present study was a double arm experimental trial. A double arm trial roughly means that the study involves two groups. Study was conducted from October $1^{\text {st }} 2019$ to $31^{\text {st }}$ October 2019. Ten rectangular wax blocks measuring $65 \times 10$ x $2.5 \pm 0.05 \mathrm{~mm}$ in length, width, and depth, respectively were made. They were fabricated using modelling wax No. 2 (Hindustan dental products, Hyderabad) (Figure 2).4 Flasking was done by the conventional method used for denture processing to create moulds for the sample preparation. To begin with the process, flasking of the wax blocks was performed with the help of type-II dental plaster. A layer of separating medium (Vaseline original, Unilever, India) was applied. Upon drying of the layer, the first counter was poured up to the base of the flask with type-II plaster. The plaster was allowed to set following which the flask was placed in a dewaxing unit. This was followed by a step of de-waxing. After the de-waxing procedure, the halves of the flask were opened and rinsed thoroughly with soap water to remove any residual wax in the mould spaces. Once the wet plaster dried the counter portion of the flask separated from the base portion was followed by a step of application of separating medium (DPI heat cure cold mould seal, Dental Products of India) (Figure 3). The halves of the flask were coated twice with the separating medium after which time was spared for it to dry. Heat polymerized polymethyl methyl acrylate acrylic resin (heat cure acrylic, Dental Products of India, Mumbai, India) was mixed according to the manufacturer's instructions (powder / liquid ratio of 3:1 was used) and packed into the mold spaces in the dough stage. The dough stage is that phase when the material cleanly separates from the sides of the jar. The material was then kneaded and packed into the customized mould spaces in the flask. A process of trial closure was performed to extract the additional material continuing further onto the plaster base.

After trimming off the excess flash the first counter portion of the flask was switched over the base of the flask. The clamps were then tightly secured manually as well as under the pressure of 30 psi under bench press to hold the flasks in position. The flasks were left for 30 to 60 minutes under pressure for the acrylic to reach its final setting time. This step was known as bench curing. Polymerization was performed for three hours in a thermostatically controlled water bath. Curing was performed using a short curing cycle $\left(74^{\circ} \mathrm{C}\right.$ for two hours and $100^{\circ} \mathrm{C}$ for an additional one hour). 

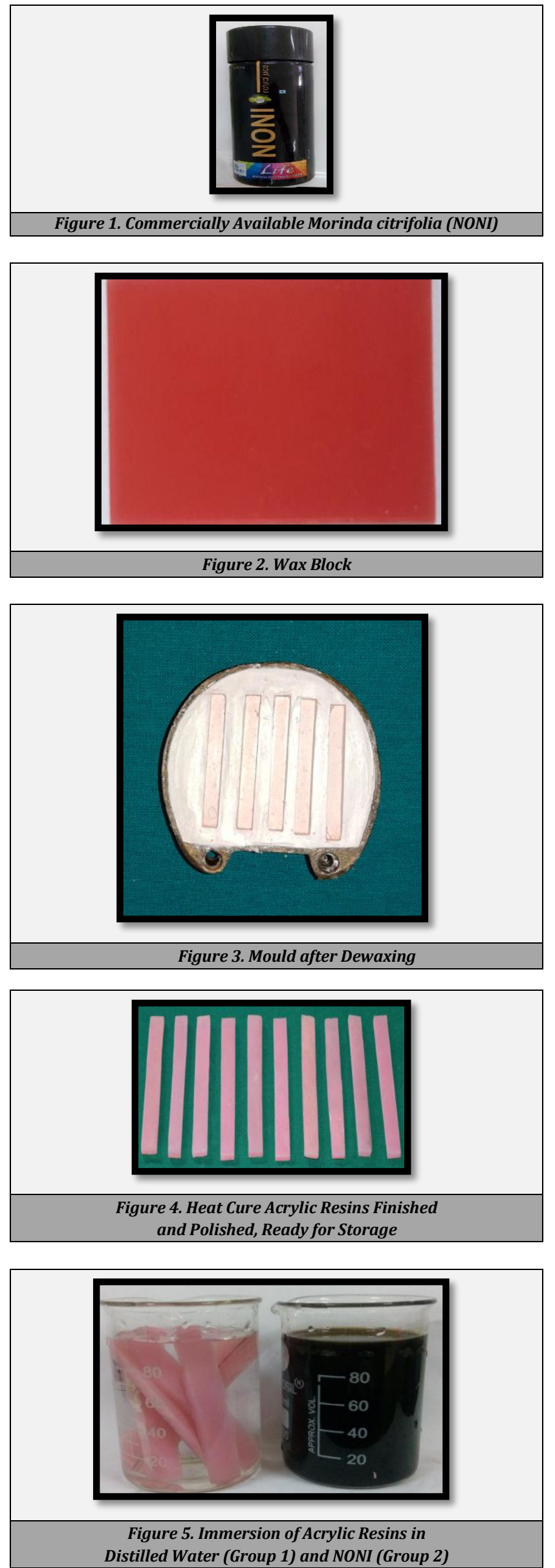

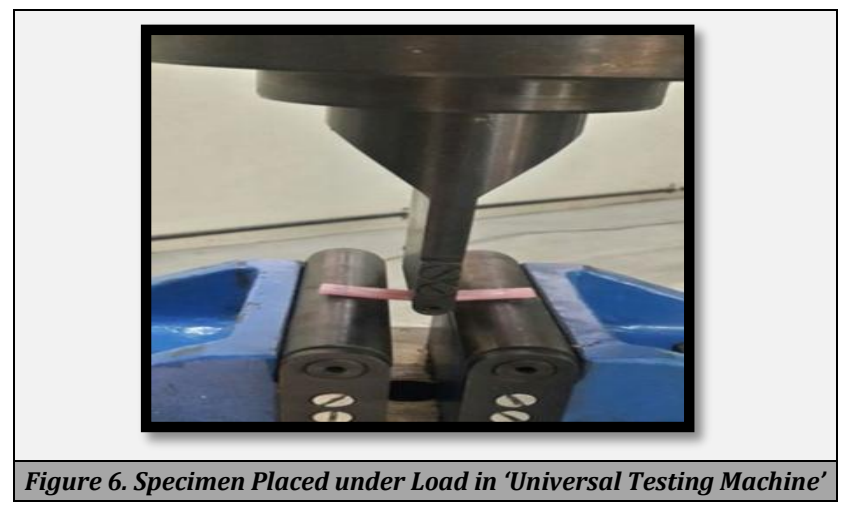

Post accomplishment of the processing time, the flask was bought out of the bath and the step of bench cooling was performed for 30 minutes. Finally, the flask was engaged under cool tap water for 15 minutes.

Careful restoration of the counter portion of the flask from the mould spaces was done. Thus, ten heat-cured polymethyl methacrylate (DPI, Dental Products of India, a division of The Bombay Burma Trading Corporation Ltd., Mumbai) moulds were obtained (Figure 4). The flasks were then opened, and acrylic rectangular slices were retrieved. The excess acrylic resin was trimmed off and the slices were marked up till the required measurement using a graphite pencil. All excess and irregular borders of the slices were finished using tungsten carbide burs. They were smoothened to proper contours using acrylic burs. Hand finishing using sandpapers of different grades such as no. 300, 600, 900, 1200, 1400, 2000, and 2500 were made use of to remove surface irregularities and to bring them to a final dimension of $65 \mathrm{~mm} \times 10 \mathrm{~mm} \times 2.5 \mathrm{~mm}$ which was measured using a digital caliper. Polishing was done with pumice and water slurry. Wet pumice was applied to a rag wheel attached to a dental lathe running at slow speed. The rectangular slices were pressed lightly against the wheel. For the final gloss, dry polishing with polishing compound and puff was used. The slices were subjected to a rouge applied to a dry muslin buffing wheel.

The slices were then divided. Out of ten samples, five samples were stored in double-distilled water (I Pure Distilled Pvt) (control group) and five were stored in Morinda citrifolia (Noni juice) (Noni, Natural Juice, K.S. Variers Ashtanga Ayurvedics, Trichy) (test group) (Figure 1) for twenty days in a sterilized beaker (Borosil, India) (Figure 5). A note was made of the date and time of storage as well as the date and time of testing for easy reference. The storage medium was renewed daily. After twenty days, the samples were removed and airdried, further on they were subjected to flexural strength testing using the Universal Testing machine (UTM) (Instron, Tamil Nadu, Chennai) (Figure 6) and values recorded. The UTM is a machine that consisted of a loading wedge and one pair of adjustable supporting wedges placed $50 \mathrm{~mm}$ apart. ${ }^{1}$ The fracture load values were then transformed to flexural strength values in Mega Pascals (MPa) which were then statistically analysed using the Mann-Whitney U-test.

\section{Statistical Analysis}

The data were analysed using the statistical software, "Statistical Package for the Social Sciences" (SPSS for Windows v.20; SPSS Inc.). Since the variables did not follow a normal distribution, a nonparametric test was applied. To compare 
the values between the flexural strength after immersion in distilled water and Morinda citrifolia, Mann Whitney U-test was performed. The significance level was fixed at $5 \%$ (P < 0.05). Mann Whitney U-test was used to compare the difference in the dependent variable for two independent groups.

\section{RESULTS}

Flexural strength values obtained for each sample after twenty days were recorded for the control group (distilled water) and test group (NONI). The values for the control group ranged from a minimum of $64.5 \mathrm{MPa}$ to a maximum of $67.5 \mathrm{MPa}$ with a mean of 66.3 and a standard deviation of 1.25 (Table 1). The values for the test group ranged from the lowest being 67.5 MPa to the highest being 72.0 MPa with a mean of 69.6 and a standard deviation of 2.01 (Table 1). The P-value was found to be 0.023 which is lower than $\mathrm{P}<0.05$, this shows that the values have consistently increased for the test group when compared to the control group. As the P-value is less than 0.05, the results are statistically significant.

\begin{tabular}{|c|c|c|c|c|c|c|}
\hline Group & $\begin{array}{l}\text { Values } \\
\text { (MPA) }\end{array}$ & Median & $\begin{array}{c}\text { First } \\
\text { Quartile }\end{array}$ & $\begin{array}{c}\text { Third } \\
\text { Quartile }\end{array}$ & $\begin{array}{c}\text { Inter Quartile } \\
\text { Range (IQR) }\end{array}$ & $\begin{array}{c}\text { P- } \\
\text { Value }\end{array}$ \\
\hline \multirow[t]{5}{*}{ Control } & 67.5 & & & & & \\
\hline & 66.0 & & & & & \\
\hline & 67.5 & 66 & 66 & 67.5 & 1.5 & \\
\hline & 64.5 & & & & & \\
\hline & 66.0 & & & & & 0.023 \\
\hline \multirow[t]{5}{*}{ Test } & 72.0 & & & & & \\
\hline & 70.5 & & & & & \\
\hline & 70.5 & 70.5 & 67.5 & 70.5 & 3 & \\
\hline & 67.5 & & & & & \\
\hline & 67.5 & & & & & \\
\hline
\end{tabular}

\section{DISCUSSION}

Removable prosthetic dentistry has a long history of making use of instruments and types of equipment's that are not easily sterilized. 5 This opens up several pathways of cross-infection and contamination between the dental laboratory assistant, the dentist, and the patient. ${ }^{5}$ Similarly, for a successful denture fabrication its proper usage as well as its longevity contributes. The prosthetic dentist plays an integral part in providing regular periodic consultation to geriatric denture patients regarding maintenance of their dentures that will prove beneficial in maintaining their longevity. ${ }^{6}$ Maintenance of dentures is also considered necessary and an integral part of fabrication. For the general health of elderly individuals, proper care of the mucosa, as well as the overlying dentures, is of utmost importance. ${ }^{6}$ As the dental team is aware of the mode of transmission of various micro-organisms depending on the procedure being performed, the need for infection control has also increased.7,1 Within just thirty minutes, all the surfaces in the mouth (whether restorations, crowns and / or even enamel) get covered by a thick precipitate of salivary glycoprotein that is commonly called as a pellicle. This layer of pellicle provides a ground onto which debris like food particles, mucin, and desquamated epithelial cells attach to. ${ }^{6}$ Thus, the prevention of microbial cross-contamination in dental laboratories among various denture prosthesis makes their storage in disinfectants mandatory. The Center for Disease Control and Prevention (CDC), as well as the American Dental Association (ADA), recommends the disinfection of dental prosthesis before sending to the dental laboratory or before delivery to the patient. ${ }^{5}$ Certain non-damaging methods of sterilization of the prosthesis are not always feasible thus methods like immersion in chemical disinfectants prove beneficial. Also, dentures when outside the mouth should be placed in water or chemical disinfectants. Chlorhexidine, sodium hypochlorite, sodium perborate is among the commonly used ones. ${ }^{8}$ Numerous studies have revealed the effects of chemical disinfectants on physical and mechanical properties of denture base resins. Thus, showing an alteration in the properties of acrylic resins with the usage of these disinfectants. A study conducted by Azevedo A (2006) ${ }^{9}$ tested the effectiveness of hypochlorite used in a concentration of 1 $\%$ and chlorhexidine at $4 \%$ on a reline material and heat polymerized denture base resin. No alterations were observed upon immersion after a week. Carvalho et al. (2012) ${ }^{10}$ tested the hardness, surface roughness, and loss of resin material after immersion in $1 \%$ sodium hypochlorite, $2 \%$ glutaraldehyde, and $4 \%$ chlorhexidine for 60 minutes. Mc Neme et al. noticed a colour change after immersion beyond the recommended time, but no change in the strength was seen. Vidya Bhat et al. (2015) ${ }^{1}$ noticed no relevant changes in the flexural strength of heat cure acrylic resin when they conducted a study that involved immersion of 75 samples of PMMA wherein 15 blocks were immersed in distilled water, while the other 30 were dipped in $4.8 \%$ sodium perborate for 8 hours and 24 hours respectively. 30 blocks were immersed respectively in $2.45 \%$ alkaline glutaraldehyde for 20 minutes and 60 minutes.

A change in the surface roughness of acrylic dentures was seen after immersion. A study conducted by Neppelenbroek et al. in the year $2005,{ }^{11}$ suggest that the chemical disinfection adversely affected the hardness of two heat polymerized denture base materials (Lucitone 550 and QC-20) and after immersion in water for fifteen days the effect was reversed and long term storage in water showed progressively increased hardness. A similar study was conducted by Pavarina $(2003)^{7}$ with the above-used denture base materials (Lucitone 550 and QC-20). The study concluded that flexural strength remained unchanged after immersion in $4 \%$ chlorhexidine, $1 \%$ hypochlorite, and $3.78 \%$ of perborate. Also, QC 20 resin displayed a transverse strength lower than Lucitone 550 resin. Asad T (1993) ${ }^{12}$ noticed no decrease or increase in values of hardness when acrylic denture base resin was dipped in some disinfectant solutions. He realized that disinfectants based on alcohol medium are not favourable for use with Trevalon, which is a cross-linked acrylic resin after immersion for up to seven days. Tsun Ma (1997) 5 observed no change in colour when "Lucitone 199 resin" was dipped in four disinfectants for a week. Recently organic disinfectants are being tested to decrease the microbial load. Thus, the present study was carried out to determine whether significant changes in the flexural strength occurred in heat-cured acrylic resin on storage in a plant extract (Morinda citrifolia). The null hypotheses stated earlier that there is no difference between the flexural properties of specimens stored in distilled water and Noni has been disproved. It is seen that flexural properties improved by immersion in Noni. 
Morinda citrifolia, a plant extract shows antimicrobial properties and pharmacological effects on the treatment of various diseases. ${ }^{6}$ Scientists have discovered a vast number of beneficial effects arising from the chemical composition of NONI. Many studies are being carried out to prove its usefulness. Selvam et al. (2009) ${ }^{8}$ studied the antibacterial effects of Morinda citrifolia and found that its extracts showed moderate antibacterial effects against E. coli, staphylococcus aureus, and Proteus Vulgaris when compared to levofloxacin. Shafath A et al. (2015), ${ }^{13}$ evaluated the anti-bacterial efficacy as well as the effect of Morinda citrifolia when mixed with irreversible hydrocolloid for dental impressions. He concluded that Morinda citrifolia mixed with irreversible hydrocolloid reduced the percentage of microorganisms when compared with water but did not affect the surface quality or dimensional stability of the casts. In the current study, a solution of leafy extract (Morinda citrifolia) showed an increase in the flexural strength after immersion in Morinda citrifolia for twenty days. Also, experiments carried out by Indiani $(2008)^{2}$ in Indonesia revealed no significant differences in the transverse strength of acrylic resin plate on immersion in Noni fruit juice for 31, 46, and 61 days. He also dipped the acrylic resin plates in Noni at various concentrations such as $4 \%, 6 \%, 8 \%, 10 \%, 12 \%$, and in distilled water after being soaked for 31,46 , and 61 days. He supported his results using a topography test on the surface of a plate fabricated of acrylic resin with the help of a light microscope with a magnification of 500x. ${ }^{2}$ Puspitasari et al. (2019) ${ }^{14}$ measured the flexural strength as well as the surface roughness of heat-cured acrylic resins when immersed in Mauli banana stem extract concentrated at a percentage of 50 $\%$. The groups used were chlorhexidine at a percentage of 0.2 , Aquadest, Mauli banana extract at a percentage of $25 \%, 37.5$ $\%$, and $50 \%$. The study revealed no changes in the resin used with any of the above-mentioned groups, thus proving that Mauli banana extract used at any concentration can be used as an alternative to a denture cleanser.

The results of the present conducted study showed that the flexural strength of the heat-cured denture base resin caused a significant increase after immersion in NONI when compared to distilled water. Since the flexural strength depends on the bulk of the material, a higher change in the strength of the material shows that most of the material was intact in the solutions. Since the flexural strength of the denture base resin increased after immersion in Morinda citrifolia it can be used safely as an everyday practice for storage of dentures.

\section{CONCLUSIONS}

Within the limitations of this study as well as based on the results obtained, it can be concluded that the flexural strength of PMMA has increased after storing in Morinda citrifolia (NONI) for twenty days when compared to storage in distilled water. Thus, proving that Morinda citrifolia (NONI) can be used as an effective storage medium for heat cure acrylic dentures without any changes in the flexural strength. The present study provides the geriatric community a herbal and beneficial alternate to all the denture cleansers and chemical disinfectants present in the market that are used as a media for denture storage.

\section{Limitations}

A potential limitation of this study was the small sample size (5 in each group). However, this study was designed to be exploratory and tried to justify using NONI as an immersion medium. Based on the positive results of the present study, we recommend further trials among patients to support / refute our findings.

Data sharing statement provided by the authors is available with the full text of this article at jemds.com.

Financial or other competing interests: None.

Disclosure forms provided by the authors are available with the full text of this article at jemds.com.

\section{REFERENCES}

[1] Bhat SV, Suhaim KS, Shenoy KK. Comparative study on effect, denture cleanser and disinfectant have on flexural strength of PMMA. Int J of Appl Dent Sci 2015;1(3):24-6.

[2] Indiani SR. The transversal strength of acrylic resin plate after being immersed soaking in Noni fruit (Morinda citrifolia Linn.) juice. Dent J (Majalah Kedokeran Gigi) 2008;41(2):84-7.

[3] Jainkittivong A, Butsarakamruha T, Langlais PR. Antifungal activity of Morinda citrifolia fruit extract against Candida albicans. Oral Surg Oral Med Oral Pathol Oral Radiol Endod 2009;108(3):394-8.

[4] Asad T, Watkinson AC, Huggett R. The effect of disinfection procedures on flexural properties of denture base acrylic resins. J Prosthet Dent 1992;68(1):191-5.

[5] Ma T, Johnson GH, Gordon GE. Effects of chemical disinfectants on the surface characteristics and color of denture resins. J Prosthet Dent 1997;77(2):197-204.

[6] Lathief J, Nandini V, Ahmed S, et al. Effect of Morinda citrifolia as storage solution on the surface roughness of heat cure acrylic resins- an invitro study. Int J of Sci Res 2018;7(6):4-6.

[7] Pavarina AC, Machado AL, Giampaolo ET, et al. Effects of chemical disinfectants on the transverse strength of denture base acrylic resins. J Oral Rehabil 2003;30(11):1085-9.

[8] Selvam P, Raj K, Vimisha V, et al. Antimicrobial activity of fruit extracts of Morinda citrifolia. Journal of Applied Chemical Research 2009;10:61-3.

[9] Azevedo A, Machado AL, Vergani CE, et al. Effect of disinfectants on the hardness and roughness of reline acrylic resins. J Prosthodont 2006;15(4):235-42.

[10] Carvalho CF, Vanderlei AD, Marcho SMS, et al. Effect of disinfectant solutions on a denture base acrylic resin. Acta Odontol Latinoam 2012;25(3):255-60.

[11] Neppelenbroek KH, Pavarina AC, Vergani CE, et al. Hardness of heat-polymerized acrylic resins after disinfection and long-term water immersion. J Prosthet Dent 2005;93(2):171-6.

[12] Asad T, Watkinson AC, Huggett R. The effects of various disinfectant solutions on the surface hardness of an acrylic resin denture base material. Int J Prosthodont 1993;6(1):912-7.

[13] Ahmed AS, Charles PD, Cholan R, et al. Antibacterial efficacy and effect of Morinda citrifolia L. mixed with irreversible hydrocolloid for dental impressions: a 
randomized controlled trial. J Pharm Bioallied Sci 2015;7(Suppl 2):S597-9.

[14] Puspitasari D, Setiawan A, Annisa DF, et al. Effects of 25 $\%, 37.5 \%$ and $50 \%$ musa acuminata extract as a denture cleanser on the flexural strength and surface roughness of acrylic resin. J Phys Conf Ser 2019;1374:012003. 